\title{
Kinetics of a Three-Step Isomerization of Glucose to Fructose Using Immobilized Enzyme
}

\author{
M. H. Gaily, A. K. Sulieman, and A. E. Abasaeed
}

\begin{abstract}
A three-step complex formation of fructose by glucose isomerization was suggested to describe the isomerization kinetics. The model was characterized by the formation of a fructose complex. Experimental data obtained from the isomerization process using immobilized Sweetzyme enzyme, IT ${ }^{\circledR}$ were used in this study. Experiments were conducted at different reaction temperatures in the range of $50-70^{\circ} \mathrm{C}$ and glucose initial concentrations of 10,15 and $20 \%$ and enzyme loading of $1 \mathrm{~g}$. Glucose concentrations dropped with time until equilibrium was reached. A first order kinetics for the steps was employed and Runge Kutta 4th order algorithm combined with a least square method were used to estimate the pre-experimental factor and activation energy for determination of the corresponding rate constants by solving the initial value problem of the suggested model using EZ-Solve software. Very good fits between experimental data and model prediction was obtained.
\end{abstract}

Index Terms - Fructose, glucose, isomerization, kinetics.

\section{INTRODUCTION}

Fructose, an isomer of glucose, is used commercially in foods and beverages industry. It is a simple sugar found in many foods and has a high relative sweetness. It is the sweetest of all naturally occurring carbohydrates and is 1.73 times the sweetness of sucrose [1]. Interest in converting glucose to fructose has attracted the attention of researchers who concentrated their efforts towards maximizing fructose yield and minimizing the costs of all associated processes [2].

Isomerization of glucose to fructose, a reversible reaction catalysed by an enzyme, is a very important industrial process to produce high fructose syrup. This enzyme was discovered in the mid of the nineteenth century and called glucose isomerase and its systematic name is d-xylose ketol-isomerase EC 5.3.1.5 [3].

Industrially, starch (a glucose polymer) is the most commonly used feedstock for production of fructose. The process depends on hydrolysing the starch into highly concentrated glucose syrup which is further processed in the presence of an isomerase. A typical process for production of fructose syrups uses alpha-amylase to liquefy starch and then

Manuscript received January 15, 2013; revised February 26, 2013. This work was supported in part by the National Science, Technology and Innovation Plan (NSTIP) at King Saud University under Grant 08-ADV391-02.

The authors are with the Chemical Engineering Department, Engineering College, King Saud University, P O Box 800, Riyadh 11421, KSA, fax: +9664678770 (e-mail: mgaily@ksu.edu.sa, Ashraf08@ksu.edu.sa, Abasaeed@ksu.edu.sa) glucoamilase to saccharify the hydrolyzed starch for the content of $94 \%$ dextrose. This resulting product will be directed for isomerization [4]. Since the conversion of glucose to fructose is equilibrium limited, the amount of fructose produced by the enzymatic isomerization reaction is related to the equilibrium constant of the reaction. A simpler purification process, based on isomerases immobilized on solid supports after the hydrolysis reaction were reported. Such processes have the advantage of reutilizing the isomerase [5], [6].

Glucose to fructose isomerization is initiated by protonation of the $\mathrm{C} 2-\mathrm{OH}$ and the formation of a furanose aldehyde intermediate. Fructose is produced via a hydride transfer from $\mathrm{C} 2$ to $\mathrm{C} 1$ on the furanose aldehyde followed by the rehydration of the $\mathrm{C} 2$ carbocation [7].

Different Models by different researchers on glucose isomerization to fructose in fluidized bed reactors were reported in the literature [8] - [15]. From the kinetic point of view, glucose to fructose isomerization is a reversible reaction that is characterized by formation of an intermediate complex [16], [17].

Kinetics of fructose-glucose isomerization in a recirculation reactor was studied [18], where Pseudo-first order kinetics was proposed in the temperature range 303-333 K, pH 7.5 and initial concentrations $0.5-2 \mathrm{~mol} / \mathrm{l}$. A generalized linear model for glucose isomerization by immobilized isomerase that satisfactorily represented the experimental data was reported [19].

Immobilized glucose isomerase from Strepomyces murinus was used in a packed bed reactor to obtain fructose from glucose and the kinetics of the isomerization is reported [20]. Also, in another study [21], glucose isomerization and fructose separation in the presence of cation-exchanged zeolites (A, X and Y zeolites) and hydrotalcites zeolites exchanged with moderate basicity ( $\mathrm{NaX}$ and $\mathrm{KX}$ ) achieved isomerization of glucose to fructose with $90 \%$ selectivity to fructose but at low glucose conversions (10-20\%). Synthesized catalysts were also used for isomerization of glucose to fructose, such process was carried out over as-synthesized Mg-Al hydrotalcite (HT_A), calcined $\mathrm{Mg}-\mathrm{Al}$ hydrotalcite (HT_C), and rehydrated $\mathrm{Mg}$ - $\mathrm{Al}$ hydrotalcite (HT_R) catalysts and it was found that rehydration process served an efficient method for increasing the catalytic performance of hydrotalcite in the isomerization of glucose into fructose [22].

The kinetics and equilibrium of isomerization reaction of D-glucose to D-fructose have been investigated using a commercial immobilized glucose isomerase (IGI), Sweetzyme type IT®, in a batch stirred-tank reactor to 
predict the concentration profiles of D-glucose and D-fructose within the reactor. The experimental results indicated that the model prediction of the transient and steady-state performance of the packed-bed reactor was satisfactory and as such could be used in the design of a fixed-bed IGI catalytic reactor [23].

In this contribution, the reaction scheme was assumed to go through two intermediate complexes; the first is a glucose-enzyme complex and the second is a fructose-enzyme complex. The kinetic investigation covers of $10-20 \%$ initial glucose concentrations and $50-70^{\circ} \mathrm{C}$ reaction temperature. An algorithm coupled with a least square method was developed to determine the relevant kinetic parameters.

\section{MAterials AND METHODS}

Three different glucose solutions of 10, 15 and 20\% were prepared separately by weighing 10,15 and 20 grams of pure glucose, respectively, and dissolving in $100 \mathrm{ml}$ deionized water. 1 gram of immobilized enzyme, Sweetzyme IT® obtained free of charge from Novozyme Company, Denmark was placed in a perforated support at the bottom of the packed bed reactor as shown in Fig. 1. A peristaltic pump was used to recirculate the glucose solution over the immobilized enzyme in the packed bed reactor at a rate of $8 \mathrm{ml} / \mathrm{second}$. The reactor was equipped with a temperature-controlled water heating jacket to maintain the temperature of the sugar solution within $\pm 0.1{ }^{\circ} \mathrm{C}$ of operating temperature. Isomerization temperatures of 50,60 and $70{ }^{\circ} \mathrm{C}$ were used with each sample. Duplicate experiments were performed.

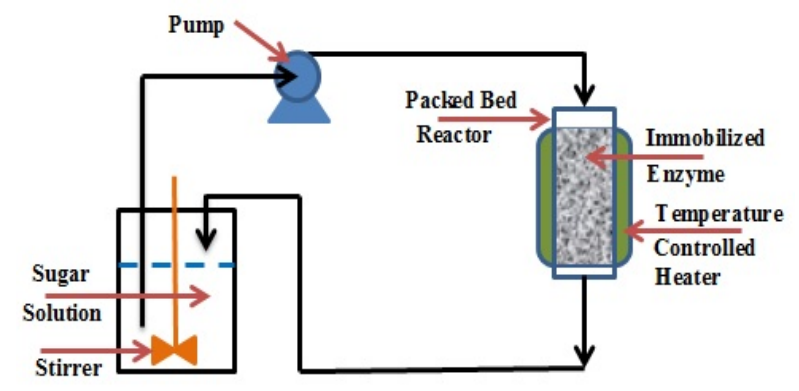

Fig. 1. Schematic diagram of the experimental set-up

Samples were analyzed for sugars concentration each two hours using High Performance Liquid Chromatograph, HPLC (Agilent 1100 series, model G1362A) equipped with IR detector. Agilent Silica based- Zorbax carbohydrate column, $4.6 \mathrm{~mm}$ ID x $150 \mathrm{~mm}(5 \mu \mathrm{m})$ was used for separating and identifying, qualitatively and quantitatively glucose and fructose in the samples collected during the isomerization process. The column temperature was set at $35^{\circ} \mathrm{C}$. $70: 30$ vol. $\%$ of acetonitrile in deionized water was used as a mobile phase at a flow rate of $1.5 \mathrm{ml} / \mathrm{min}$.

\section{RESUlTS AND DiscUSSIONS}

Glucose isomerization was assumed to proceed via a three-step process that involves the formation of two complexes (glucose-enzyme and fructose-enzyme) as shown below.

$$
G+E \underset{k_{2}}{\stackrel{k_{l}}{\longleftrightarrow}} \mathrm{GE} \underset{k_{4}}{\stackrel{k_{3}}{\longleftrightarrow}} F E \underset{k_{6}}{\stackrel{k_{5}}{\longrightarrow}} F+E
$$

where $\quad G=$ glucose; $\quad F=$ fructose; $\quad E=$ enzyme; $\mathrm{GE}=$ glucose-complex; $\mathrm{FE}=$ fructose complex.

$k_{1}, k_{3}$ and $k_{5}$ are the forward reaction rate constants for first, second and third steps respectively.

$k_{2}, k_{4}$, and $\mathrm{k}_{6}$ are the backward reaction rate constants for first, second and third steps respectively.

The kinetic investigation covered a reaction temperature range of $50-70^{\circ} \mathrm{C}$ and initial glucose concentrations ranging from $10 \%-20 \%$. The model assumes reversible first order kinetics for the three steps. The rate constants associated with the model and the corresponding activation energies and pre-exponential factors are evaluated using Runge Kutta $4^{\text {th }}$ and the least square method for minimization of errors. Rate constants are assumed to follow Arrehenius expression, i.e,

$$
k_{i}=k_{i o} e^{-\frac{E_{i}}{R T}}
$$

The activation energy $\left(E_{i}\right)$ can be obtained from the slope of the graph when $\ln \left(k_{i}\right)$ is plotted against $(1 / \mathrm{T})$; the pre-exponential factor $\left(k_{i 0}\right)$ can obtained from the intercept of the same equation.

\section{A. Model Development}

$$
\begin{gathered}
-\frac{d(G)}{d t}=k_{1}(G)(E)-k_{2}(G E) \\
\frac{d(G E)}{d t}=k_{1}(G)(E)-\left(k_{2}+k_{3}\right)(G E)+k_{4}(F E) \\
\frac{d(F E)}{d t}=k_{3}(G E)-\left(k_{4}+k_{5}\right)(F E)+k_{6}(F)(E)
\end{gathered}
$$

Let:

$$
\begin{gathered}
K_{3}=\frac{k_{1}}{\left(k_{2}+k_{3}\right)} \text { and } K_{4}=\frac{k_{4}}{\left(k_{2}+k_{3}\right)} \\
L_{3}=\frac{k_{3}}{\left(k_{4}+k_{5}\right)} \text { and } L_{6}=\frac{k_{6}}{\left(k_{4}+k_{5}\right)}
\end{gathered}
$$

Applying the quasi-steady state assumption for the two complexes, i.e.,

$$
\frac{d(G E)}{d t}=0 \quad \text { and } \quad \frac{d(F E)}{d t}=0
$$

Equations (2) and (3) become:

$$
\begin{gathered}
K_{3}(G)(E)-(G E)+K_{4}(F E)=0 \\
L_{3}(\mathrm{GE})-(F E)+L_{6}(F)(E)=0
\end{gathered}
$$

Solving e (4) and (5) simultaneously, gives:

$$
(G E)=\frac{\left[K_{3}(G)+K_{4} L_{6}(F)\right](E)}{\left(1-K_{4} L_{3}\right)}
$$

And

$$
(F E)=\frac{\left[L_{3} K_{3}(G)+L_{6}(F)\right](E)}{\left(1-K_{4} L_{3}\right)}
$$

Let: $M_{3}=\frac{K_{3}}{\left(1-K_{4} L_{3}\right)} \quad$ and $\quad M_{6}=\frac{L_{6}}{\left(1-K_{4} L_{3}\right)}$ 
Substituting into (GE) and (FE) above, gives:

$$
\begin{gathered}
(G E)=\left[M_{3}(G)+K_{4} M_{6}(F)\right](E) \\
(F E)=\left[L_{3} M_{3}(G)+M_{6}(F)\right](E)
\end{gathered}
$$

Enzyme balance:

$$
\left(E_{o}\right)=(E)+(G E)+(F E)
$$

Substituting from (6) and (7) into (8), one gets:

$$
\begin{gathered}
\left(E_{\mathrm{o}}\right)=(E)+\left[M_{3}(G)+K_{4} M_{6}(F)\right](E)+\left[L_{3} M_{3}(G)+M_{6}(F)\right](E) \\
\left(E_{o}\right)=\left[1+\left(1+L_{3}\right) M_{3}(G)+\left(1+K_{4}\right) M_{6}(F)\right](E) \\
(E)=\frac{E_{o}}{\left[1+\left(1+L_{3}\right) M_{3}(G)+\left(1+K_{4}\right) M_{6}(F)\right]}
\end{gathered}
$$

Substituting (6) and (9) into (1), one gets

$$
\begin{gathered}
-\frac{d(G)}{d t}=\frac{\left[\left(k_{1}-k_{2} M_{3}\right)(G)-k_{2} K_{4} M_{6}(F)\right] E_{o}}{\left[1+\left(1+L_{3}\right) M_{3}(G)+\left(1+K_{4}\right) M_{6}(F)\right]} \\
(F)=\left(G_{0}\right)-(G)
\end{gathered}
$$

\begin{tabular}{|c|c|c|c|c|c|c|c|}
\hline \multicolumn{2}{|r|}{$\mathrm{T},{ }^{\circ} \mathrm{C}$} & k1 & k2 & k3 & k4 & k5 & k6 \\
\hline \multicolumn{2}{|r|}{50} & 0.14 & 0.15 & 0.11 & 0.33 & 0.61 & 0.69 \\
\hline \multicolumn{2}{|r|}{60} & 0.51 & 0.39 & 0.29 & 0.59 & 0.91 & 1.13 \\
\hline \multicolumn{2}{|r|}{70} & 1.48 & 0.66 & 0.75 & 0.9 & 2.17 & 2.1 \\
\hline $\begin{array}{l}\mathbf{T}, \\
\mathbf{K}\end{array}$ & 1/TK & $\ln (k 1)$ & $\ln (k 2)$ & $\ln (k 3)$ & $\ln (k 4)$ & $\ln (k 5)$ & $\ln (k 6)$ \\
\hline 323 & 0.003096 & -1.966 & -1.897 & -2.207 & -1.109 & -0.494 & -0.371 \\
\hline 333 & 0.003003 & -0.673 & -0.942 & -1.238 & -0.528 & -0.094 & 0.122 \\
\hline 343 & 0.002915 & 0.392 & -0.416 & -0.288 & -0.105 & 0.775 & 0.742 \\
\hline
\end{tabular}

\section{1) Rate constants estimation}

Table I shows the values of the rate constants $\left(k_{1}, k_{2}, k_{3}\right.$, $k_{4}, k_{5}, k_{6}$ ) obtained from data at reaction temperatures of 50 , 60 and $70^{\circ} \mathrm{C}$ using a least square method for parameter estimation. The table, also shows the values of $\ln \left(k_{i}\right)$ and $1 / \mathrm{T}$

TABLE I: RATE CONSTANTS FOR ESTIMATIONS

For each reaction, the activation energy $E_{i}$, $\left(\mathrm{cal}^{\mathrm{m}} \mathrm{mol}^{-1} \mathrm{~K}^{-1}\right)$ and the pre-experimental factor $k_{i o},\left(\mathrm{~h}^{-1}\right)$ can be obtained from the slopes and intercepts of plots of $\ln (k i)$ versus $(1 / T)$. These values are tabulated in Table II.

TABLE II: ACTIVATION ENERGY AND RATE CONSTANT FOR DIFFERENT

\begin{tabular}{|c|c|c|}
\hline \multicolumn{3}{|c|}{ REACTIONS } \\
\hline Reaction, $\mathbf{i}$ & $\boldsymbol{E}_{\boldsymbol{i}}, \mathrm{cal}^{\mathrm{m} \mathrm{mol}^{-1} \mathrm{~K}^{-1}}$ & $\boldsymbol{k}_{\boldsymbol{i} \boldsymbol{o}}, \mathrm{h}^{-1}$ \\
\hline 1 & 25974 & $5.40 \times 10^{16}$ \\
\hline 2 & 16350 & $1.85 \times 10^{14}$ \\
\hline 3 & 21124 & $2.15 \times 10^{13}$ \\
\hline 4 & 11057 & $1.02 \times 10^{7}$ \\
\hline 5 & 13912 & $1.46 \times 10^{9}$ \\
\hline 6 & 12233 & $1.28 \times 10^{8}$ \\
\hline
\end{tabular}

\section{B. Overall Predictions}

Values of the activation energy $\boldsymbol{E}_{\boldsymbol{i}}$, and the pre-experimental factor from Table(2) are used in equation (1) to obtain the corresponding rate constants by solving the initial value problem given by equation (12) using EZ-Solve software. The predictions of the model against corresponding experimental values are illustrated in Figs. (2-4) for initial glucose concentrations of $20 \%, 15 \%$ and $10 \%$ and reactions temperatures of 50,60 and $70^{\circ} \mathrm{C}$. As shown by the figures good agreement is obtained.

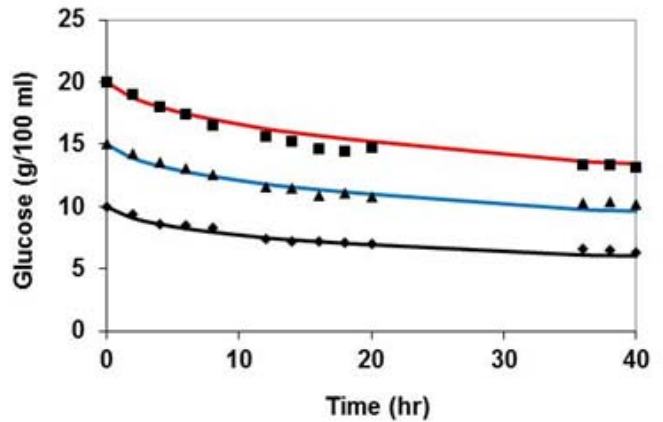

Fig. 2. Comparison of model predictions (solid lines) with experimental values (symbols) at $50^{\circ} \mathrm{C}$ and at different initial concentrations of glucose $(\bullet=10 \%),(\boldsymbol{\Delta}=15 \%)$ and $(\mathbf{m}=20 \%)$

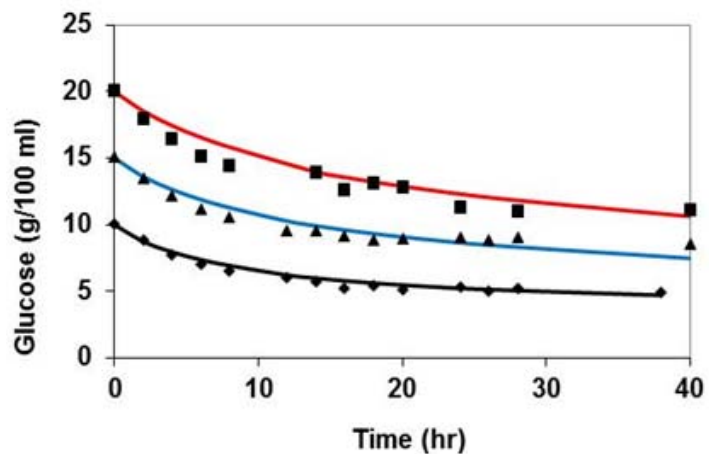

Fig. 3. Comparison of model predictions v(solid lines) with experimental values (symbols) at $60{ }^{\circ} \mathrm{C}$ and at different initial concentrations of glucose $(\bullet=10 \%),(\boldsymbol{\Delta}=15 \%)$ and $(\boldsymbol{\varpi}=20 \%)$

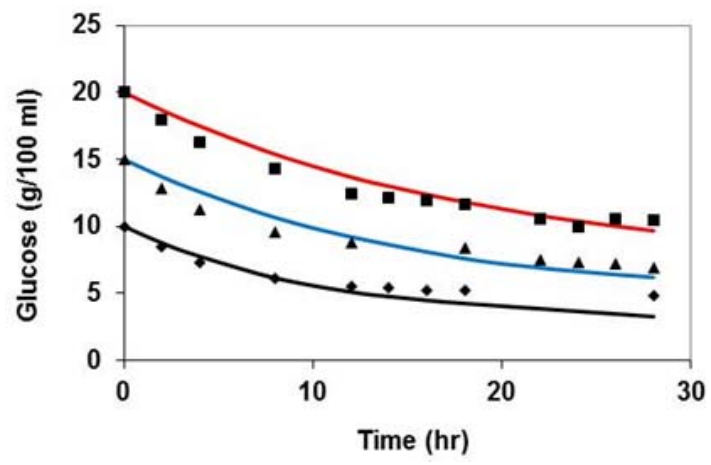

Fig. 4. Comparison of model predictions (solid lines) with experimental values (symbols) at $70{ }^{\circ} \mathrm{C}$ and at different initial concentrations of glucose $(\bullet=10 \%),(\boldsymbol{\Delta}=15 \%)$ and $(\mathbf{-}=20 \%)$

\section{CONCLUSION}

Glucose isomerization into fructose reaction was performed in a batch reactor of a fixed working volume of $250 \mathrm{ml}$ using an immobilized isomerase. The reaction conditions covered a wide range of parameters' values: reaction temperatures $\left(50-70{ }^{\circ} \mathrm{C}\right)$, initial glucose concentrations $(10-20 \%)$ and initial enzyme loadings $(0.5-$ $1.5 \mathrm{~g})$. Preliminary experiments revealed those reaction temperatures of $40{ }^{\circ} \mathrm{C}$ or less requires prohibitively long reaction times and those higher than $70{ }^{\circ} \mathrm{C}$ imparts colors on sugar solution due to caramelization. As expected, isomerization of glucose proceeds with reaction time until an equilibrium concentration is reached. Depending on reaction temperatures, the equilibrium position changes; a fact confirmed by the kinetics. 
A three-step two-complex kinetic expression that represents a three-step formation of fructose and has six rate constants was suggested and its associated parameters were evaluated using a least square method for minimizing errors.

Reactions as presented are considered to be elementary and follow first order kinetics.

Very good fits between experimental data and model predictions were generally obtained.

\section{ACKNOWLEDGMENT}

The authors extend their appreciation to the National Science, Technology and Innovation Plan (NSTIP) at King Saud University for their generous support and funding of this study as a part of project \# 08-ADV391-02.

\section{REFERENCES}

[1] L. M. Hanover and J. S. White, "Manufacturing, composition, and application of fructose," Journal of Clinical Nutrition, vol. 58, pp. 724S-732S, November 1993.

[2] T. P. Mawhinney, M. A. Madson, and M. S. Feather, "The isomerization of d-glucose in acidic solutions", Carbohydrate Res., vol. 86, pp. 147-150, November 1980.

[3] R. Khalilpour and R. Roostaazad, "Development and verification of a model to describe an immobilized glucose isomerase packed bed bioreactor," Biochemical Engineering Journal, vol. 40, pp. 328-336, June 2008.

[4] H. O. Hultin, "Current and potential uses of immobilized enzymes," Food Technol, vol. 37, pp. 66-82, 1983.

[5] J. Straatsma, K. Vellenga, H. G. deWilt , and G. E. Joosten, "Isomerization of Glucose to Fructose 2, Optimization of Reaction Conditions in the Production of High Fructose Syrup by Isomerization of Glucose Catalyzed by a whole cell Immobilized Glucose Isomerase Catalyst," Ind. Eng. Chem. Proc. Des. Dev., vol. 22, pp. 356-361, July 1983.

[6] E. A. B. D. Silva, A. A. Ulson D. Souza, S. G. U. D. Souza, and A. E. Rodrigues, "Analysis of the high-fructose syrup production using reactive SMB technology," Chemical Engineering Journal, vol., 118, pp. 167-181, May 2006.

[7] X. Qian and X. Wei, "Glucose isomerization to fructose from ab initio molecular dynamics simulations," J. phys Chem, vol. 116, no. 35, pp. 10898-10904, August 2012.

[8] C. B. Ching and K. H. Chu, "Modeling of a fixed bed and a fluidized bed immobilized enzyme reactor," Appl. Microbiol. Biotechnol, vol. 29, pp. 316-322, June 1988.

[9] G.A. Oertzen, N. Kalogerakis, L.A. Behie, T. Kiesser, and W. Bauer, "Dynamic and steady state modeling of an immobilized glucose isomerase fluidized bed bioreactor" in Proc. International Conference on Fluidization, Fluidization IV, New York, N.Y, 1988, pp. 491-498.

[10] T. D. Papathanasiou, N. Kalogerakis, and L. A. Behie, "Dynamic modelling of mass transfer phenomena with chemical reaction in immobilized-enzyme bioreactors," Chem. Eng. Sci., vol. 43, no. 7, pp. 1489-1498, July 1988.

[11] T. Kiesser, A. O. Gustav, and W. Bauer, "Modeling of a fluidized bed bioreactor for immobilized enzymes (Part 1)," Chem. Eng. Technol., vol. 13, pp. 20-26, February 1990a.

[12] T. Kiesser, A. O. Gustav, and W. Bauer, "Modelling of a fluidized bed bioreactor for immobilized enzymes (Part 2)", Chem. Eng. Technol., vol. 13,pp. 80-85, February 1990b.

[13] M. Asif, and A. E. Abasaeed, "Modeling of glucose isomerization in a fluidized bed immobilized enzyme bioreactor," Bioresource Technol., vol. 64, pp. 229-236, June 1998.
[14] A. E. Abasaeed, M. Asif, and A. H. Fakeeha, "Zeolite-catalyzed hydrolysis of inulin in a fluidized bed reactor," Bioprocess Eng, vol. 20, pp. 343-351, June 1999.

[15] M. H. Gaily, B. M. Elhassan, A. E. Abasaeed, and M. Al-Sharhan, "Isomerization and kinetics of glucose into fructose," International Journal of Engineering and Technology, vol. 10, no. 3, pp. 1-5, June 2010.

[16] A. Kikkert, K. Vellenga, H. G. J. D. Wilt, and G. E. H. Joosten, "The isomerization of D-glucose into D-fructose catalyzed by whole-cell immobilized glucose isomerase. The dependence of the intrinsic rate of reaction on substrate concentration, $\mathrm{pH}$, and temperature," Biotech Bioeng, vol. 23, pp. 1087-1101, May 1981.

[17] V. Braveo, E. Jurado, G. Luzon, and N. Cruz, "Kinetics of fructoseglucose Isomerization with sweetzyme type A," The Canadian J. of Chem. Eng, vol. 76, pp. 778-783, 1998.

[18] F. C. Rubio, E. J. Alameda, P. G. Tello, and G. L. Gonzalez, "A comparative study of the activity of free and immobilized enzymes and its application to glucose isomerase," Chem. Eng. Sci., vol. 51, pp. 4159-4165, February 1996.

[19] P. Emilio and C. Attilio, "Evaluation of diffusional resistances in the process of glucose isomerization to fructose by immobilized glucose isomerase," Enzyme and Microbial Technology, vol. 28, pp. 246-252, February 2001.

[20] H. S. Lee and J. Hong, "Kinetic of glucose isomerization to fructose by immobilized glucose isomerase :anomeric reactivity of D-glucose in kinetic model," J. Biotechnol., vol. 84, pp. 145- 153, November 2000.

[21] C. Moreau, R. Durand, A. Roux, and D. Tichit, "Isomerization of glucose into fructose in the presence of cation-exchanged zeolites and hydrotalcites," Appl. Catal. A: Gen., vol. 193, pp. 257-264, February 2000.

[22] S. Yu, E. Kim, S Park, I. K. Song, and J. C. Jung, "Isomerization of glucose into fructose over $\mathrm{Mg}-\mathrm{Al}$ hydrotalcite catalysts," Catalysis Communications, vol. 29, pp. 63-67, December 2012.

[23] A. M. Dehkordi, L. Safari, and M. M. Karima, "Experimental and modeling study of catalytic reaction of glucose isomerization: Kinetics and packed bed dynamic modeling," AICHE Journal, vol. 54, no. 5, pp. 1333 - 1343, May 2008.

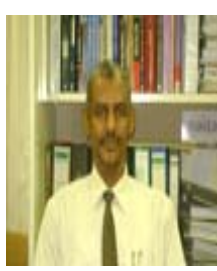

Mohamed H. Gaily was born in Sudan, on $21^{\text {st }}$ November. He has obtained his $\mathrm{Ph}$. D. degree in Chemical Engineering in the year 2010 from Chemical Engineering Department, University of Khartoum, Sudan. M. Sc. Degree in Agricultural Process Engineering in the year 1999 from Process and Food Engineering Department, College of Engineering, Universiti Putra Malaysia, Malaysia and B. Sc. in Chemical Engineering in 1992 from Chemical Engineering Department, Faculty of Engineering and Architecture, University of Khartoum, Sudan. He is working as a researcher in Chemical Engineering Department, Engineering College, King Sauid University in Saudi Arabia. He was also worked as a lecturer at University of Khartoum. He has published several research articles in the field of biochemical engineering. His research interests in the field of production of high fructose syrup from dates, fermentation and bio-fuel. In May $17^{\text {th }} 2011$ he registered, with others, a US patent \# 7942972 describing a method of separating fructose and glucose. Dr. Gaily is a member for Saudi Chemical Engineering Society and Saudi Chemical Society. He obtained Al-Masmak Distinction Plates Award from King Saud University for distinguished research, publication and registration of an international patent (US patents), Riyadh, for the year 2011/2012. He worked for academic accreditation committee and strategic plan committee for Engineering College at King Sauid University, Saudi Arabia. 